\title{
RE-DESIGN OF ADDITIVE MANUFACTURED SPARE PARTS BASED ON FEATURES CLASSIFICATION
}

\author{
J. Montero ${ }^{1,2, \otimes}$, S. Weber ${ }^{1,2}$, M. Bleckmann ${ }^{2}$ and K. Paetzold ${ }^{1}$ \\ ${ }^{1}$ Bundeswehr University Munich, Germany, ${ }^{2}$ Bundeswehr Research Institute for Materials, Fuels and Lubricants, \\ Germany \\ $\bigotimes$ j.montero@unibw.de
}

\begin{abstract}
Additive Manufacturing is doing its first steps in the production of spare parts. Usually the spares belong to legacy systems, and the tooling to produce them is no longer available. Re-designing spares that are designed for a previous industry mindset can be sometimes challenging. In this study a rather classic design approach is compared to a functional driven approach. Four case studies from different clients are reported, remarking the benefits and drawbacks of using design for additive manufacturing practices in Laser Powder Bed Fusion.
\end{abstract}

Keywords: additive manufacturing, case study, design for $x(D f X)$, laser powder bed fusion (L-PBF), spare parts

\section{Introduction}

It is of public knowledge that $3 \mathrm{D}$ printing (or additive manufacturing, AM) market size has not stopped growing steadily, with special focus in the metal area, where the market revenues have been increasing by $40 \%$ annually during the last five years (Wohlers Associates, 2019). Together with the hype, the applications of this technology have been expanding at a slower pace. Nonetheless, new applications are being discovered on a daily basis (Seibold, 2018), and are added to the current portfolio which includes areas such as medicine, naval and aerospace.

An application field that is relatively new is the production of AM spare parts. Since AM can rapidly produce complex geometries, the spare parts industry took an interest in it, especially for those components whose tooling is not available for some reason. AM spares are also a good alternative for the applications that demand fast spares or emergency repairs. For instance, the integration of AM in the supply chain has demonstrated being a great asset for the military (Montero et al., 2018).

These spares are usually from outdated machinery or legacy systems. As these systems are relatively old the technical documentation can be unavailable, a fact that represents an obstacle for designers. To generate the digital spare, i.e. the CAD files, it is necessary to do a reverse engineering stage and a redesign to make the spare printable.

There are different ways to tackle the tasks of the mentioned re-design stage. This contribution presents four use cases designed in two different ways, and compares the technical results along with the opinion and feedback of the end user. The latter are medium/large enterprises which perform maintenance tasks for the German Federal Armed Forces. 
Using 3D printing to re-manufacture parts which are meant to be fabricated with a previous industry mindset, can be a tedious and difficult task if it is not well approached (Atzberger et al., 2018). As any other manufacturing method, AM has its limitations (Adam and Zimmer, 2015). Understanding them is key to reach printing success (Booth et al., 2017). This study highlights the necessity of communicating these limitations to the final user, so that realistic designs can be achieved in common agreement with the designers.

\section{State of the art}

\subsection{Additive manufacturing}

Additive Manufacturing (AM, also known as 3D printing) is defined by the ISO/ASTM 5900 standards as the process of joining materials to make parts using 3D model data, usually layer upon layer, as opposed to subtractive manufacturing and formative manufacturing methods (ASTM, 2015). AM is applicable to many materials such as polymers, metals or ceramics and therefore different AM technologies with different TRL (technology readiness level) are currently available. Some of the main advantages (in contrast to subtractive manufacturing) are their ability to form complex geometries, the opportunity of ondemand manufacturing and the possibility of creating customized parts in a low volume production.

Usually the term Design Freedom is associated to AM, giving the idea that AM can realize any geometry. This is not entirely correct, since depending on the AM technology and material, some physical restrictions apply (Ponche et al., 2014). The research area studying design possibilities and how to overcome these restrictions, to produce AM components successfully is called Design for AM (DfAM) (Thompson et al., 2016), including design models, methods, processes and tools. Standards on DfAM requirements guidelines and recommendations are established under the ISO/ASTM 52910-18, (F42 Committee, n.d., p. 42) for generic use cases. Due to the constantly increasing number of AM applications, there is a need to have more process and material specific guidelines in order to avoid elevated number of design iterations. Several efforts are underway in this direction, a good example of that is the recent contribution of (Allison et al., 2019) giving insight of how to develop $D f A M$ guidelines based on a metrology study.

\subsubsection{Laser powder bed fusion}

Powder Bed Fusion (PBF) is one of the seven categories of AM processes defined by ISO/ASTM 52900 standards (ASTM, 2015). A PBF process uses a powder bed and a focused energy source to fuse material powder at specific points determined by 3D data. Layers are produced using a build plate as substrate, once a layer is completed the build plate lowers down and a new layer of powder is spread, repeating the process till the 3D object is finished. Laser Powder Bed Fusion (L-PBF), is a subclass of the PBF processes that uses a laser beam as energy source and a roller as material spreader. Metal L-PBF uses metallic powder as raw material, among the most studied are the alloys Al10SiMg and Ti6Al4V. The building chamber requires an inert gas atmosphere in order to prevent the L-PBF parts from oxidizing during the build. A schematic of an L-PBF machine is shown in Figure 1.

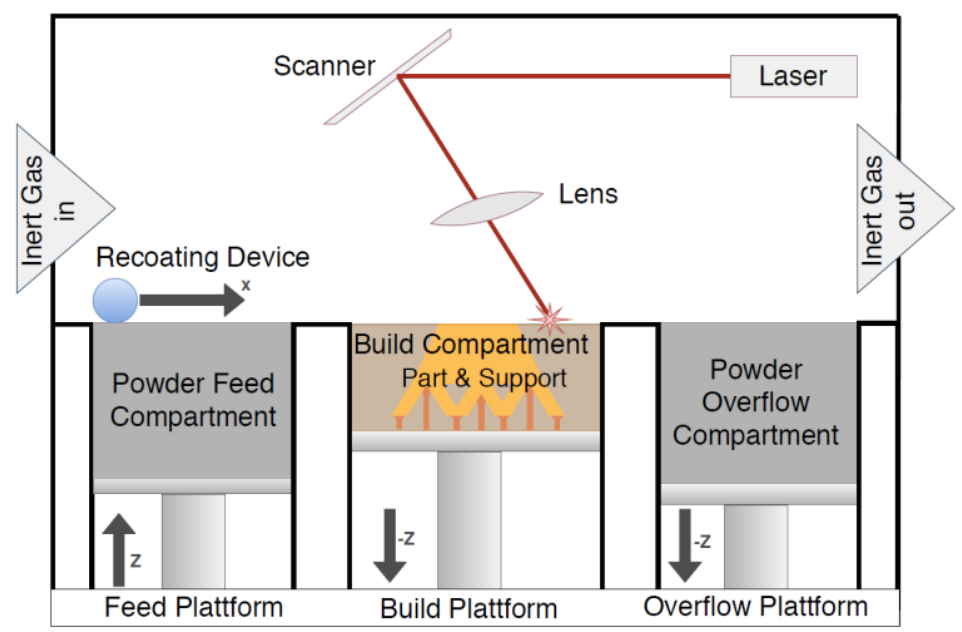

Figure 1. Schematic of L-PBF process 
L-PBF method requires support structure generated from the same material as the part. Support structure anchors the part to the build plate, dissipates the heat and prevents object from thermal distortion originated from residual stresses. After the process is finished, the part is physically attached to the build plate with the support structure. To obtain the final part, post-treatment has to be performed, which usually include depowdering, thermal treatments (aging, quenching, hot isostatic pressing), support removal and finishing (machining operations). Selective Laser Melting (SLM) (Meiners et al., 1997), and Direct Metal Laser Sintering (DMLS) (Shellabear and Nyrhilä, 2004), are popular names for Metal L-PBF processes.

\subsection{AM of spare parts}

As AM is evolving from a technology used for rapid prototyping to a technology rapid manufacturing, the applications in the industry begin to emerge markedly. Among these applications are the fabrication of spare parts and the integration of AM in the supply chain (Khajavi et al., 2014). Due to its capabilities, AM can rapidly produce complex geometries in small batches. A recent study (Ballardini et al., 2018), highlighted that the use of AM for the production of spare parts in the short-term, is particularly relevant in the case of legacy systems. This stems from the fact that AM can facilitate the replacement, redesign or repair of components for obsolete machines for which tooling facilities no longer exist.

Additionally, AM is a great asset for reducing delivery times of spares and warehouse storing, since AM facilities can be deployed to the operation area. Nowadays, the use of AM spares has particularly impacted in industries where the spare cost is not a relevant factor, since some AM spares can be expensive, but as the technology reaches maturity the costs will decrease (Thomas and Gilbert, 2014).

The use of AM spares is gaining importance in Germany, which is leading the industrial implementation of 3D printing in Europe, with the special drive of the automotive industry (Bridget O'Neal, 2019). The report from (Geissbauer et al., 2017) revealed that within the next five years $85 \%$ of the German part-suppliers will incorporate 3D printing into their business and in 10 years the suppliers will save up to $€ 3$ billion annually by using AM.

\subsubsection{Design of $A M$ spares}

As this article focuses on spares that are no longer in production, i.e. discontinued, it is likely that the part has meant to be manufactured with a traditional manufacturing method. In addition, since legacy spares date a few decades old, is common that the technical documentation is lost or not available. This entails that generating a digital file for manufacturing usually includes a reverse engineering stage of the original spare.

AM methods have different tolerances than conventional manufacturing methods. For example, LPBF has a minimum feature size that limits the resolution of the produced part, depending on the laser spot, the energy induced in the material and the thermal conductivity of the powder. There are as well other limitations, like the impossibility of creating large cross sections and excessive overhangs. To consider these limitations, the designers follow a set of guidelines, recommendations and rules of thumb defined in the DfAM research field. DfAM is mostly focused in the creation of new designs with novel techniques within an open design space. In order to apply that knowledge to old designs, the area of Adaptation for Additive Manufacturing (AfAM) stands, which is the redevelopment of an existing product design to better suit the design constraints imposed by AM (Brigden, 2016). The latter have a less open design space which makes it more challenging to apply it, since old spares designs have been created with a different industry mindset.

The application of AfAM is a complex task and sometimes requires numerous design iterations to successfully produce the AM spare (Montero et al., 2019). When these adaptions are utilized incorrectly, AM could produce parts of an inferior quality that were more expensive to fabricate (Ballardini et al., 2018). This is because the original materials of the spares and their manufacturing processes are highly matured and standardized, while AM is just starting to establish itself as production manufacturing process. 


\section{Methods}

In this contribution the re-design of spare parts to be additively manufactured is studied. The part requests are normally submitted by third parties, referred as clients. Most of the times these requests are to make components from legacy systems.

Producing an AM spare normally requires a reverse engineering $(R E)$ procedure. Since the designers in this area have to adapt the design many times to comply with AM tolerances and the AM constraints, the process is considered to be a re-design rather than just RE. A previous study details the re-design of spare parts to be produced trough $\mathrm{AM}$, highlighting that $3 \mathrm{D}$ printing of a 3D scan is not sufficient to meet minor quality requirements (Montero et al., 2018).

There are some CAD tools for doing RE on parts that recognize features on top of scanned files automatically. This might be sufficient for simple parts, but in more complex cases the correct parametrization and hierarchies in the feature tree are fundamental to perform redesign activities and $A f A M$. Furthermore, it is essential to have high unconstrained parametric part designs, to enable future design iterations (Montero et al., 2019), this is key to realize fast improvements after a potential failed print job. Common causes for failed print jobs using L-PBF are an unperfected set of machine parameters, large cross-sections, insufficient support structure and inappropriate posttreatment.

The part to be re-designed is considered a component of a system or assembly, and is defined as a set of geometrical features. In order to obtain an AM spare, the designers have to recreate the mentioned set of features. Hence, two design approaches are proposed and compared. The first approach is close to creating a replica, with a design focus on making the part look exactly like the original, assuming that the functionality will also be the same. The second approach is more engineering driven, and allows enhancements, optimization and DfAM improvements. By using this way, the part works like the original or even better, but the lookalike aspect is relegated to a second plane. Since the responsibility of the design team is bigger in the approach $\mathrm{B}$, because they are actively modifying the original design, the spare parts redesigned in this way have intensive testing $\&$ validation. The latter contribute to improve the quality and performance of the new spare, delivering in most cases better part reliability. Both approaches are explained in detail in the following subsection.

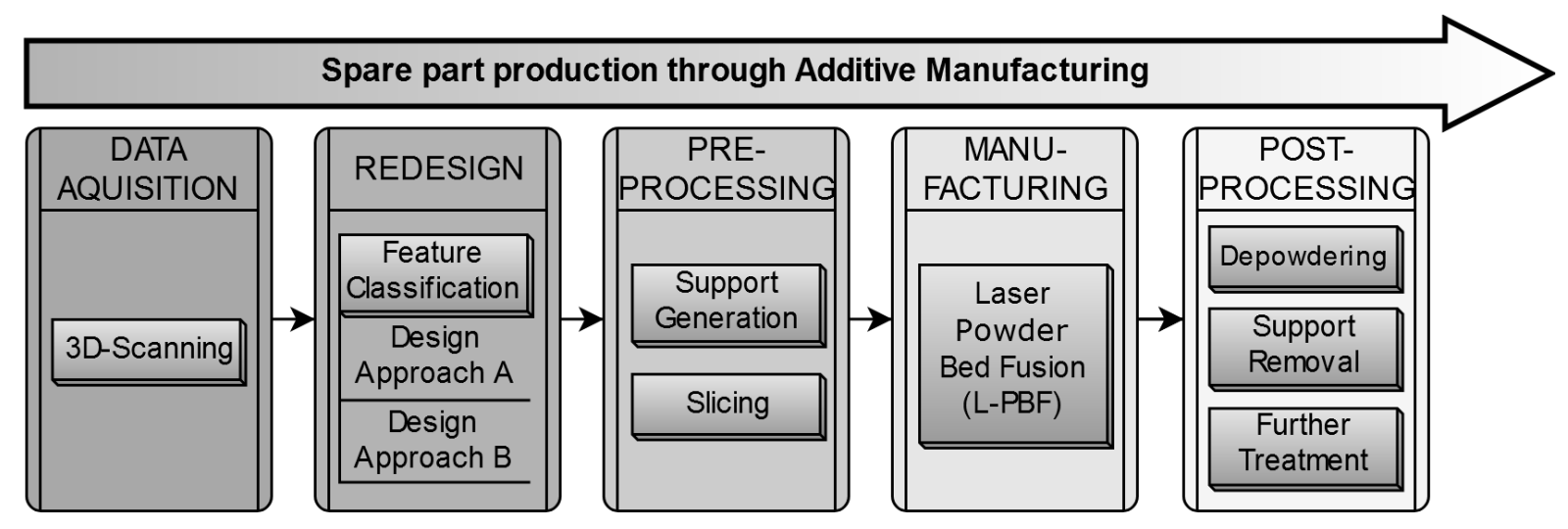

Figure 2. AM Spare part production process

In order to describe the difference between the mentioned approaches, in first place, a features classification scheme is introduced:

\section{Features of 1st Hierarchy (Features I)}

Features that compromise the technical functionalities and compromise the performance of the spare part, as well as essential features that determine the functions of the part as a component in an assembly. Examples are fixation points, holes, pads and relevant distances, any shape that might place another component, bushings or bearing holds. Furthermore, any feature that is considered of high relevance for the specific part or component fits in this group as well. 


\section{Features of 2nd Hierarchy (Features II)}

Features that do not impact on the expected function of the component but affect the handling or manipulation by the user, or the ease of assembly in a component group. Examples are assembly marks, guides, grips, printed instructions, fillets or chamfers of sharp edges.

\section{Features of 3rd Hierarchy (Features III)}

Features inherent to the former manufacturing method, i.e., features that are on the part exclusively for manufactural reasons. An example are the draft angles used in casting parts, casting defect or marks, bending marks and die marks. In this group the features that are merely cosmetic and add nonfunctional value to the part are added, like branding marks, logos or watermarks, printed unnecessary codes and ornaments.

\subsection{Design approach $\mathbf{A}$}

This approach is the classic re-design that is normally done when a request reaches the design department. All features I, II \& III are accounted for, delivering a design that is usually a direct copy of the original part and has a high level of geometric constraints. The functionalities of the part are not enhanced by allowing improvements and geometrical modifications. The part is finished when it looks like the original and deploys the same functions with similar performance. Expectable outputs of this approach are rigid designs, with a low level of parametrization and difficulties to be further adapted if the spare does not meet the requirements of the client. In the case of failed print jobs, the design iterations are harder to perform due to a lack of design flexibility.

By following approach A, the designers focus on the form and shape of the part, but bypassing that the original design was made for a different manufacturing method. Furthermore, this approach does not consider the special characteristics of AM, in particular L-PBF, e.g. surface properties, thermal distortion, different response to thermal treatment, and anisotropy.

\subsection{Design approach B}

Since metal L-PBF is one of the most geometry dependant AM technologies (Parry et al., 2019), the parts usually have to go under $D f A M$ practices in order to have a successful print job. This approach encourages the designer to focus just in the Features I, freely adapting them to obtain a fully functional spare that might not look like the original. The Features II and III are neglected for this approach, and in case any of those features are explicitly required by the client or compromise the performance, they are added to the design as Features-additional.

This way of re-designing fits a top-down design strategy (Mantyla, 1990). Compared to the approach $A$, it exploits that design freedom that is inherent AM and is centred only in the functionality of the part.

The main goal is to have a manufacturable AM part, which has the same functions as the original with the same or better performance. Designs achieved using approach B are flexible, easy to modify and adaptable in case the requirements are changed. In the case of failed print jobs, this approach is easy to iterate after the parameters are corrected.

\section{Experimental results}

The parts reported in this study are received as 3D scanned files, these could be cloud point files or triangulated STL files. The first type is often preferred, since the triangulated files add some noise and uncertainty to the dimensions. All the scanned files seem to represent casted parts, by judging the draft angles on the walls and casting marks on the surfaces. According to the information given by the client, the original material for all of them is aluminium or an aluminium alloy, so the used process is L-PBF with AlSi10Mg material. The L-PBF manufacturing system used is the SLM Solutions ${ }^{\circledR} 280$, and the manufacturing parameters are set following the recommendations of (Kempen et al., 2015).

Both design approaches had been applied to 4 different use cases from different clients in the same industry, maintenance of military equipment. $\mathrm{Al}$ the use cases are spares belonging to military ground mobility solutions and stationary auxiliary equipment. 
The results in terms of number of features are shown in Table $1 \&$ Table 2 . To double check the information given by the designers, the design time is taken from the file history metadata. The built volume represents the volume of the part plus the volume of the support structure, reflecting printing time and printing cost. The variable built volume is chosen since the material cost depends on a set of factors, as batch size, supplier, reusing of the powder and market price. The same happens with the machine manufacturing time, as this is dependent on the type of machine, layer height scan strategy and laser spot size. Using built volume as manufacturing time/cost substitute make this analysis independent from machine and powder cost parameters.

Table 1. Report of spare part design, approach A

\begin{tabular}{|l|c|c|c|c|c|c|}
\hline Part & F I & F II & F III & Design Time & Built Volume & \% Vol. Support \\
\hline Spare 1 & 28 & 6 & 16 & $8 \mathrm{~h}$ & $102325 \mathrm{~mm}^{3}$ & 17 \\
\hline Spare 2 & 14 & 4 & 12 & $4 \mathrm{~h}$ & $73439 \mathrm{~mm}^{3}$ & 19 \\
\hline Spare 3 & 47 & 7 & 11 & $5 \mathrm{~h}$ & $124291 \mathrm{~mm}^{3}$ & 21 \\
\hline Spare 4 & 23 & 6 & - & $5 \mathrm{~h}$ & $51234 \mathrm{~mm}^{3}$ & 5 \\
\hline
\end{tabular}

Table 2. Report of spare part design, approach B

\begin{tabular}{|l|c|c|c|c|c|}
\hline Part & F I & F-additional & Design time & Built Volume & \% Vol. Support \\
\hline Spare 1 & 28 & 2 & $4 \mathrm{~h} 20 \mathrm{~min}$ & $96734 \mathrm{~mm}^{3}$ & 12 \\
\hline Spare 2 & 21 & 1 & $1 \mathrm{~h}$ & $63382 \mathrm{~mm}^{3}$ & 15 \\
\hline Spare 3 & 47 & 3 & $6 \mathrm{~h}$ & $112303 \mathrm{~mm}^{3}$ & 8 \\
\hline Spare 4 & 23 & - & $2 \mathrm{~h} 30 \mathrm{~min}$ & $49186 \mathrm{~mm}^{3}$ & 5 \\
\hline
\end{tabular}

The variable \% vol support expresses the percentage of the built volume that embodies the support structure. This is reported in order to know, how much of the raw material is invested in support structure, since this material is not possible to re-use. Also, this variable gives an idea of how big the support structure is. Since support is attached to the printed part, the larger the more post-processing has to be applied.

The percentage variations of the reported variables are shown in Figure 3. An improvement of using the approach B can be observed, shown as a notable reduction of the variables, that is expected since the work load is smaller. To highlight, the design time was reduced $75 \%$ in the best case.
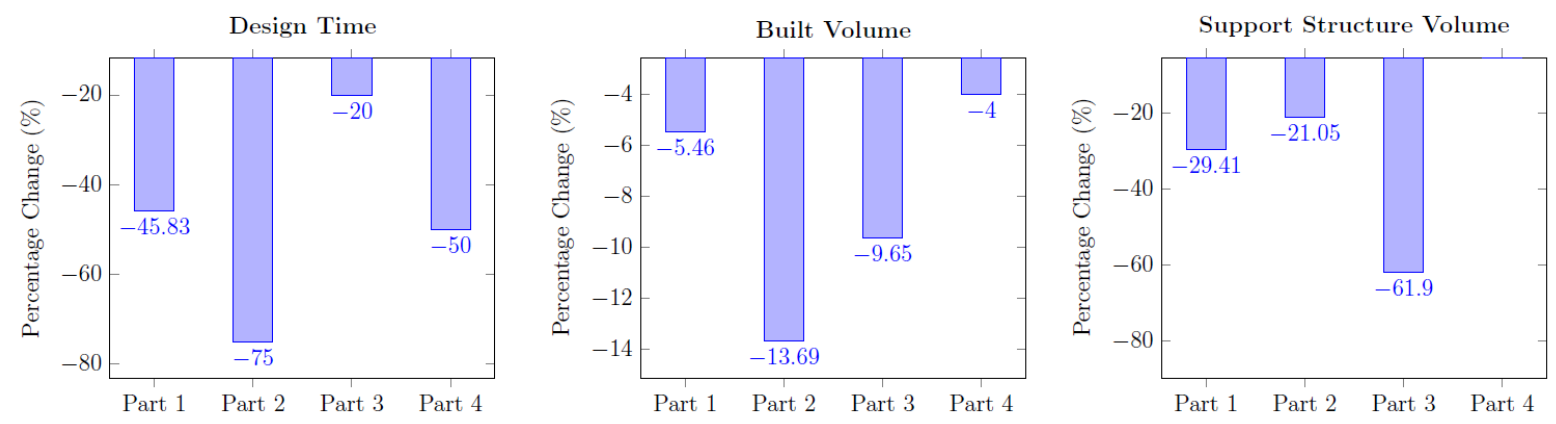

Figure 3. Improvements of design approach B over approach A

By using the approach B, the modifications were similar in all the spares (creation of fillets and rounding sharp edges, subtracting of unnecessary features, and reinforcements where the original spares presented issues). Additionally, in the re-design of Spare 3, topology optimization was applied since it was known the stress requirement. The Features-additional from spare $1,2 \& 3$ were necessary assembly marks that could not be deleted since were elemental for the integration of the spare in the system.

To understand better the variables determining the cost a further analysis is done for the Spare 3. Even though Spare 3 is the biggest, i.e. has the biggest Built Volume, the Design Time spent is not the longest in the Approach A. This is because this part did not have complex features on it, and many of 
its features could be easily reproduced by the designers and did not represent a challenge for the used AM method. But the results change for the Approach B, since it has a big number of FI features with respect to the other analysed Spares. The reason is that, optimizing for AM so many features without losing continuity on the model surfaces, takes longer.

After delivering each re-designed spare, for both approaches, the client is inquired via phone call to know if the AM spare meet the expected requirements. To put in evidence if the client is reluctant to aggressive re-designs, the AM spare produced with the approach B was delivered in the first place, so in that way the clients do not have anything to compare with. The spare produced with the approach A, was delivered after their reply of approval (or disapproval). The acceptance by the client was optimal for the approach A, since the spares looked like the originals, there was no complain or hesitation at the time of using them. The client acceptance rate of the AM spares following the approach A was $100 \%$. In the case of the spares produced following the approach B, the acceptance rate was $25 \%$, i.e., 3 out of 4 parts got rejected by the client. The only part that got accepted without hesitation was the Spare 4. This is because the number of non-primary features was low, so the final design looks similar for both approaches.

Because of confidentiality reasons the reported re-designed spares cannot be explicitly shown in this contribution, instead of that an example realized via both approaches is shown in Figure 4. The only difference with the reported use cases, is that this part has not been requested by a client. In this case the original spare was scanned with a Creaform ${ }^{\circledR}$ Handyscan ${ }^{\mathrm{TM}} 3 \mathrm{D}$ scanner, and redesigned on Inventor ${ }^{\mathrm{TM}}$. In a second design iteration the part was optimized via Ansys ${ }^{\circledR}$ (topology optimization with strain energy minimization, overhang constraint to allow angles only $>45^{\circ}$ ) and redesigned using Spaceclaim ${ }^{\mathrm{TM}}$. The adding of support structure and creation of machine files is done using Materialise ${ }^{\circledR}$ Magics.

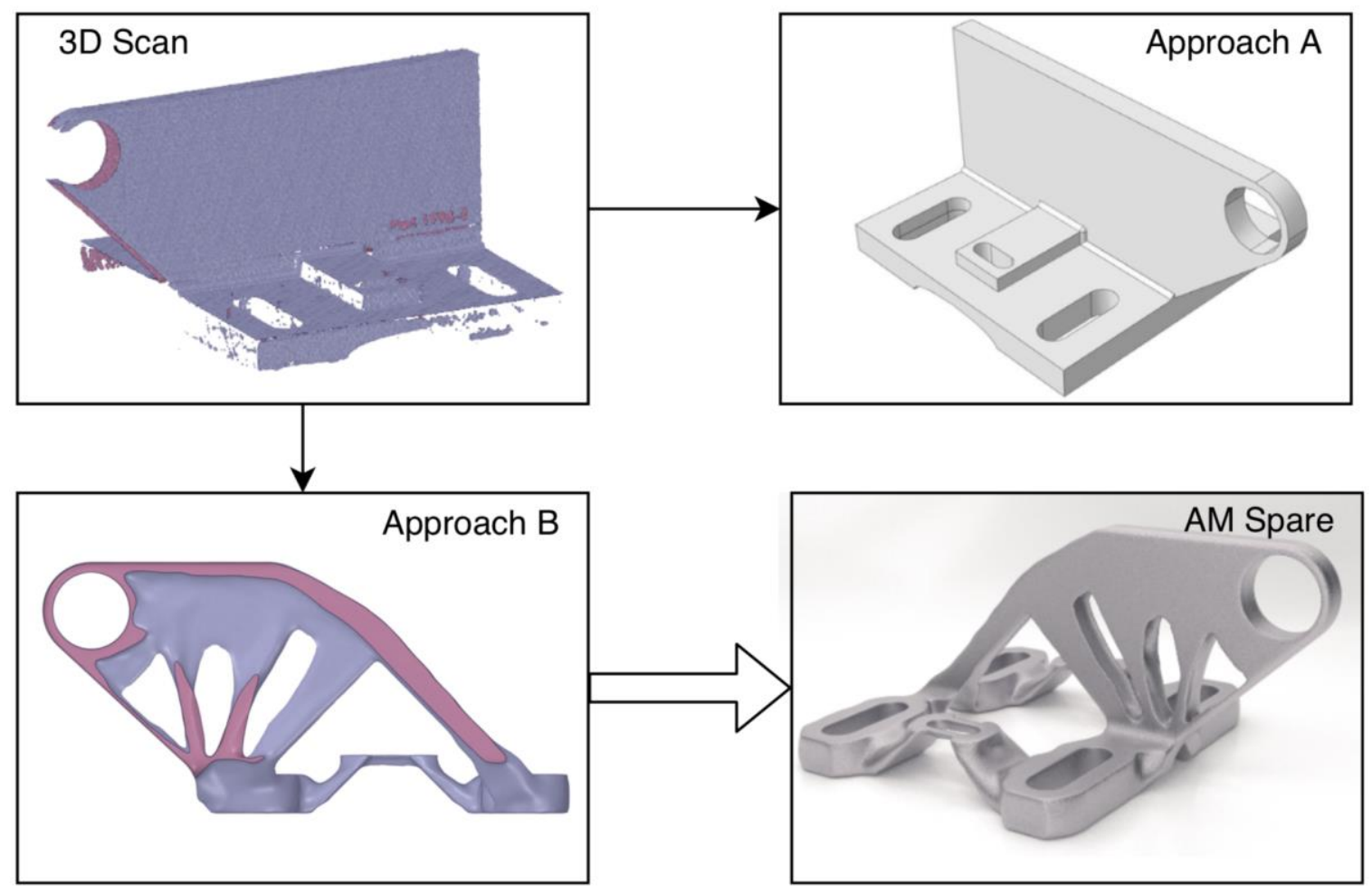

Figure 4. AM spare results, comparison of both design approaches

\section{Summary \& conclusion}

This contribution presents two different approaches to design AM spare parts based in a feature classification scheme. The approach $\mathrm{A}$ is more an adaptation of a spare, with special focus on the lookalike of the original spare. The approach B is functionality-driven and allows the modifications of 
DfAM. Four use cases were reported and compared using both design approaches for the L-PBF method. Designers explained that the more unrestrained the design space is, the better results can be achieved since it is easier to exploit the possibilities that the selected AM method provides.

By following the approach B, the designs were lighter, cheaper and faster, marked by the reductions in the built volume and design time. The applied support structure was smaller compared to the approach A, a fact that leads to material savings. Overall the spares fabricated following the approach B were mechanically slightly better and involved lower costs.

On the other hand, approach a needed further design-manufacturing iterations and more manufacturing volume to replicate the extra features.

Even though the spares B performed better in the design department, the spares A were preferred by the client, having an acceptance rate of $100 \%$ against the $25 \%$ of the spares B. Clients justified the rejection by expressing that if the spare already existed and performed well, they did not want any improvement on the part, i.e., they ask for the exact copy. This is due to the fact that clients prefer the spare that looks "like the original" to reduce risks, and they do not contemplate the fact that AM also has manufacturing constraints which sometimes make it really challenging for the AfAM to obtain a perfect replica. Additionally, the military maintenance industry has very rigid standards, thus the maintenance operators work with a conservative mindset that could reduce the acceptance of innovative spares. In essence the clients know the capabilities of AM, but they prefer rather traditional "safe" designs than innovative improved new ones, even though they could perform worse.

This can be explained by the recent hype of AM. The press has established the idea that anything can be done via 3D printing, that there is an infinite design freedom paradigm, making the expectations of the clients really high for producing replicas. It is important to clarify to potential customers which are the AM limitations, especially in the area of Metal AM, where the processes are more geometry restrictive than in other AM methods. Explaining this clearly to clients before offering the service appears to be the solution, at least until the limitations become popular among end users.

The AM spare parts production is under the early stage of development, and as such, more research in the area is needed. The authors encourage designers to get involved in the creation of new design processes, considering the vast knowledge in DfAM guidelines available. In this way, more modified spare designs will emerge, and they will be become better known among final users.

Besides the client acceptance of design modifications, there are still many obstacles that the AM spares have to overcome to succeed in the market. Some of these obstacles are legal implications and the quality certifications, topics that are under intense investigation in the AM community.

\section{References}

Adam, G.A.O. and Zimmer, D. (2015), “On design for additive manufacturing: evaluating geometrical limitations", Rapid Prototyping Journal, Vol. 21 No. 6, pp. 662-670.

Allison, J., Sharpe, C. and Seepersad, C.C. (2019), "Powder bed fusion metrology for additive manufacturing design guidance", Additive Manufacturing, Vol. 25, pp. 239-251.

ASTM, I. (2015), "ASTM52900-15 Standard Terminology for Additive Manufacturing - General PrinciplesTerminology", ASTM International, West Conshohocken, PA.

Atzberger, A. et al. (2018), "Characteristics of a metal additive manufacturing process for the production of spare parts", Symposium on Design for X, Vol. 29, pp. 83-94.

Ballardini, R.M., Flores Ituarte, I. and Pei, E. (2018), "Printing spare parts through additive manufacturing: legal and digital business challenges", Journal of Manufacturing Technology Management, Vol. 29 No. 6, pp. 958-982.

Bridget O'Neal. (2019), "Big Push in Germany to Enable 3D Printing in Automotive Industry". 3DPrint.Com | The Voice of 3D Printing/Additive Manufacturing, 17 April, available at: https://3dprint.com/241657/ germany-big-push-bmbf-ibam-instill-3d-printing-am-processes-automotive-industry/ (accessed 15 November 2019).

Booth, J.W. et al. (2017), “The Design for Additive Manufacturing Worksheet”, Journal of Mechanical Design, Vol. 139 No. 10, p. 100904.

Brigden, K. (2016), "Adaptation for AM versus Design for AM", presented at the Additive Manufacturing Users Group, St. Louis, 25 April, available at: https://www.slideshare.net/KevinBrigden/adaptation-for-am-versusdesign-for-am (accessed 13 November 2019). 
F42 Committee. (n.d.). "Guidelines for Design for Additive Manufacturing”, ASTM International, available at: https://doi.org/10.1520/F3154-18

Geissbauer, R., Wunderlin, J. and Lehr, J. (2017), Partner, PwC Strategy \& Germany.

Kempen, K. et al. (2015), "Processing AlSi10Mg by selective laser melting: parameter optimisation and material characterisation”, Materials Science and Technology, Vol. 31 No. 8, pp. 917-923.

Khajavi, S.H., Partanen, J. and Holmström, J. (2014), “Additive manufacturing in the spare parts supply chain”, Computers in Industry, Vol. 65 No. 1, pp. 50-63.

Mantyla, M. (1990), “A modeling system for top-down design of assembled products”, IBM Journal of Research and Development, Vol. 34 No. 5, pp. 636-659.

Meiners, W., Wissenbach, K. and Gasser, A. (1997), Selective Laser Sintering at Melting Temperature, Aachen, 27 October.

Montero, J. et al. (2019), “Anwendung agiler Entwicklungsprinzipien für die Herstel-lung von Ersatzteilen mit additiven Fertigungsverfahren”, Konstruktion für die Additive Fertigung., 2019th ed.

Montero, J. et al. (2018), "Re-Design and Re-Manufacturing of Discontinued Spare Parts Implementing Additive Manufacturing in the Military Field", presented at the 15th International Design Conference, pp. 1269-1278.

Montero, J., Weber, S. and Bleckmann, M. (2019), "Spare part production in remote locations through Additive Manufacturing enhanced by agile development principles", p. 9.

Parry, L.A., Ashcroft, I.A. and Wildman, R.D. (2019), "Geometrical effects on residual stress in selective laser melting”, Additive Manufacturing, Vol. 25, pp. 166-175.

Ponche, R. et al. (2014), "A novel methodology of design for Additive Manufacturing applied to Additive Laser Manufacturing process", Robotics and Computer-Integrated Manufacturing, Vol. 30 No. 4, pp. 389-398.

Seibold, M. (2018), "Why we drive the industrialization of Additive Manufacturing", Linked In, 20 September, p. 5.

Shellabear, M. and Nyrhilä, O. (2004), "DMLS - Development History and State of the Art", LANE 2004 Conference, presented at the LANE 2004, Erlangen, Germany, p. 12.

Thomas, D.S. and Gilbert, S.W. (2014), Costs and Cost Effectiveness of Additive Manufacturing, No. NIST SP 1176, National Institute of Standards and Technology, p. NIST SP 1176.

Thompson, M.K. et al. (2016), "Design for Additive Manufacturing: Trends, opportunities, considerations, and constraints", CIRP Annals, Vol. 65 No. 2, pp. 737-760.

Wohlers Associates. (2019), Wohlers Report 2019: 3D Printing and Additive Manufacturing State of the Industry. 
